\title{
LAS MIGRACIONES Y EL ENVEJECIMIENTO DE LA POBLACIÓN ${ }^{1}$
}

Jaime Martín Moreno*

Dice un proverbio mexicano: "No pidas a Dios que te dé. Pídele que te ponga donde hay". A los Magrebies, a los Subsaharianos, a los Latinoamericanos los está poniendo Dios donde hay: en España, en la Europa rica y vieja.

España es, en el año 2001, uno de los países más ricos del mundo y uno de los más viejos. Como paso obligado de Africa y de Latinoamérica a Europa tiene todas las características para ser un país de inmigración. En Madrid se va a construir el mayor aeropuerto europeo. No es casualidad. Hasta hace poco, en España teníamos un Instituto Nacional de Emigración, ahora tenemos un Ministerio de Inmigración que es realmente lo que representa la Delegación del Gobierno para la Inmigración.

La migración, tanto si es legal como ilegal, puede alterar profundamente a una comunidad o a todo un país en muy poco tiempo. El sur y el este de España es un ejemplo. La migración representa, junto con la fecundidad y la mortalidad, uno de los fenómenos básicos en demografía. Se diferencia de la natalidad y mortalidad en muchos aspectos, además de los obvios. Para empezar tenemos que la migración resulta muy difícil de medir. Sabemos menos sobre ella que sobre la mortalidad o la fecundidad. Ello significa que lo que sabemos acerca de las complejas razones por la que la gente emigra es aún menos que lo que sabemos acerca de por qué tienen hijos (cuestión esta compleja) y de por qué mueren. Por otro lado, y a pesar de ello, la migración ha sido objeto de un control gubernamental mucho mayor que la fecundidad y la mortalidad, y al mismo tiempo los gobiernos son muy reacios a dar información clara y continuada de la misma.

* Profesor Titular, Departamento de Ecología Humana y Población de la Universidad Complutense de Madrid y miembro de la Asociación Castellano-Manchega de Sociología. 
España y Europa es una región de inmigración (tanto legal como ilegal) en la que los individuos no cesan de moverse, como si buscasen otro lugar casi mágico que pudiera ofrecer más de lo que ya hay. A medida que los individuos se trasladan contribuyen al crecimiento y al cambio de la población tanto a corto como a largo plazo. La migración constituye un proceso demográfico de considerable importancia. La migración hay que verla como solución al envejecimiento de la población.

Se calcula que en el mundo hay 150 millones de inmigrantes. Y, desde comienzos de los años 90 , entre 300.000 y 500.000 personas es el flujo anual de inmigrantes en Europa. Los inmigrantes clandestinos representan uno por cada cuatro y su número se calcula entre 19 y 38 millones.

En España, Italia, Grecia, Portugal y Alemania acogen a casi 3 millones de "sin papeles". Rusia ha recibido en la última década 500.000 inmigrantes clandestinos, procedentes de la ex URSS, Asia, Africa y Medio Oriente. Nadie habla de estas cifras. Las guarda celosamente la Organización Internacional para las Migraciones (OIM). Son estimaciones solventes, no datos, puesto que, por definición, las autoridades desconocen el carácter clandestino y los gobiernos son reacios a comunicar sus cifras a los organismos internacionales.

Pero no basta con luchar contra las mafias. Nadie puede ser ajeno al origen de esa inmigración que es la miseria, la falta de libertades, la imposibilidad legal de luchar contra las dictaduras, el integrismo, el analfabetismo. Cualquiera de esos inmigrantes clandestinos pudo haber exclamado, ¡Yo escogí la libertad! ${ }^{2}$.

La UE se ha comprometido a luchar contra el tráfico de inmigrantes ilegales. El gran reto es tratar de integrar a esa mano de obra cada vez más necesaria. Tira de la mano de obra extranjera en sectores como la construcción, la agricultura o el servicio doméstico y en aquellos otros altamente cualificados donde escasea el talento. Pero las relaciones con los inmigrantes son ambivalentes.

Según la ONU, Europa va a necesitar en los próximos 25 años alrededor de 160 millones de extranjeros. El aspecto positivo de la inmigración legal es evidente. Un trabajo del Instituto Universitario de Estudios sobre Migraciones, de la Universidad Pontificia de Comillas, puede enriquecer el debate con algunas cifras. En el caso de España, los inmigrantes legalmente establecidos costaron a las arcas públicas 651.5 millones de euros en el año 1998, en concepto de recepción de refugiados, atención sanitaria, seguridad sanitaria, etc. Pero muchos de ellos trabajan, pagan sus impuestos y aportaron a Hacienda 1.653 millones de euros, cantidad superior a los gastos que generan. Con estas cifras, no hace falta recurrir a la solidaridad para plantear la conveniencia de tomarse en serio a los trabajadores extranjeros.

Aunque hay una tendencia general, a nivel mundial, al envejecimiento, los países desarrollados tuvieron la suerte de hacerse ricos antes de hacerse viejos. Los subdesarrollados, desgraciadamente, empezarán a envejecer antes de hacerse 
ricos. Para el año 2050 países pobres y, sobre todo los países ricos estaremos frente a un problema tan temible como fue en su día el temor de la superpoblación: el envejecimiento.

En 1950 había cuatro jóvenes por adulto en el planeta, se tenían 5 hijos de media y la esperanza de vida era menos de 60 años. El discurso de entonces era catastrofista por exceso de población. Ahora surge otro, más realista y pesimista, por el envejecimiento de la población.

España no es ajena a este problema. En el 2050 será el país más viejo del mundo. El mismo problema se percibe en Italia donde los sociólogos han decidido hacer un llamamiento a la población: "Es imposible sostener una sociedad tan envejecida como ésta". La relación entre el envejecimiento y la inmigración parece evidente.

España, si sus políticos no lo remedian y si sus habitantes siguen con la misma actitud que hasta ahora, va caminando poco a poco hacia la consecución del record de la población más envejecida del mundo. Ello significa muchas cosas. Por lo pronto, las pensiones de los que ahora, en el año 2001, tienen más de 15 años, puede ser algo de lo que oyeron hablar a sus abuelos y de lo que ellos carecerán si las cosas permanecen como hasta ahora. No hay sociedad que resista un envejecimiento tan alto sin modificar la edad de la jubilación. El envejecimiento de la población es una consecuencia de la bajada de la natalidad y de la bajada de la mortalidad. Si no entra ni sale población, ésta se acumula en las edades más altas y, paulatinamente, el total de la misma va descendiendo. De seguir así las cosas, la ONU calcula que España tendrá en el 2050 entre diezy doce millones de habitantes menos. De los 40 millones actuales pasaríamos a 30 o 32 millones dentro de 50 años. Hay algunos rasgos demográficos que puede que ocurran en España durante este siglo XXI que entra. Demos algunas pistas:

1. Un indicador transparente es el que expresa la edad media que tiene en conjunto la población. Mide el nivel de envejecimiento. En el año 2000 España no aparece entre los 10 primeros países con la edad media más alta del mundo. Los países que le superan son (por este orden): Japón $(41,2)$, Italia $(40,2)$, Suiza $(40,2)$, Alemania (40,1), Suecia (39,7), Finlandia (39,4), Bulgaria (39,1), Bélgica $(39,1)$, Grecia $(39,1)$ y Dinamarca $(39,7)$. Pues bien, en el año 2.050 España será la nación del mundo con la "edad media" $(55,2)$ más alta (tabla $\left.{ }^{\circ} 1\right)$. En sólo medio siglo, el número de españoles pasará de los 40 millones actuales a 32 millones, con una edad media en torno a los 55 años.

2. Otro indicador complementario al anterior es el \% de población mayor de 60 años. España ocupa en el año 2000 el $7^{\circ}$ lugar del mundo con un 21,8. Italia, Grecia, Alemania, Japón, Suecia y Bélgica están por delante. Dentro de 50 años España conseguirá auparse al primer lugar del mundo con un $\%$ de población mayor de 60 años del 44,1\%. Frente al envejecimiento de España y del resto de los países europeos, observamos cómo los 10 países más jóvenes del mundo son mayoritariamente subsaharianos. Parece obvio que estos países 
sean los que más población proporcionen a la inmigración clandestina, población que utiliza las ya tristemente famosas pateras para atravesar el Estrecho de Gibraltar con destino a España y resto de Europa. (tabla $n^{\circ} 2$ ).

3. En el año 2000 España no aparece entre la 10 primeros países mundiales con menor tasa de crecimiento natural. En el año 2050 no sólo aparece sino que se colocará como el segundo país con menor tasa de crecimiento natural del mundo después de Italia. Todo un record que nos avisa de la bajísima natalidad que tenemos y que, por lo que se sabe, vamos a seguir teniendo $\left(\operatorname{tablan}^{\circ} 3\right)$. Si no tenemos hijos, alguien (los inmigrantes) los tendrán que tener por nosotros.

El caso de España, como hemos podido observar, empieza a ser paradigmático dentro de Europa. Conviene que dirijamos la vista a más altura y rastreemos el territorio de la Unión Europea que es el contexto dentro del que España se encuentra y del que recibe las mayores influencias en cuanto al comportamiento poblacional y a su atractivo inmigratorio.

A partir del año 2005 la población de la UE tendrá más peso de mayores de 65 años que de niños menores de 15. Es la pirámide invertida. En el año 2050 el peso de los mayores será de casi un $20 \%$ y el del los niño apenas llegará a un $14 \%$. El problema consiste, fundamentalmente, en que ese proceso no tiene posibilidad de vuelta por la sencilla razón de que el peso relativo de las mujeres en edad reproductiva (15-49 años) descenderá notablemente a partir del año 2000 (gráfico $\mathrm{n}^{\circ} 1$ ). De nuevo hay que recurrir a la inmigración con remedio al envejecimiento y a la disminución de la mortalidad.

La disminución de la población en la Unión Europea es tan previsible que cualquier organismo que intente hacer su cáculo no puede menos que certificarlo. La ONU lo hace y sólo pronostica un aumento tomando la hipótesis más optimista, y, por tanto, la menos esperada. Con esta hipótesis en los próximos 50 años la población de la Unión Europea se incrementaría en 9 millones de habitantes, magra ganancia en tan largo trecho. Lo normal es que se cumplan la previsiones de su hipótesis media y que la población descienda en el próximo medio siglo en unos 40 millones de habitantes si la inmigración no lo remedia. En la más pesimista de las hipótesis en 50 años se perderían casi 80 millones (gráfico n ${ }^{\circ} 1$ ). Este previsión de la ONU dibuja una figura gráfica que podríamos denominar el árbol caído de la población europea.

La pirámide resultante en la proyección de la ONU no puede ser más expresiva: pasa de una figura normal en 1950 a una pirámide invertida 100 años después, en el 2050. Curiosamente es palpable el peso de la mujer en el grupo de edad de más de 85 años (gráfico n ${ }^{\circ} 2$ ).

Lo anterior es el resultado lógico de la previsiones de lo que va a ocurrir en la primera mitad del siglo XXI por lo que respecta a la esperanza de vida, la edad media y la mortalidad infantil en el territorio de la Unión. Desde 1950 
hasta el 2050 las mujeres europeas habrán ganado más de 16 años de Esperanza de vida media y 14 años lo hombres. La edad media habrá pasado de 32 a 48 años. La mortalidad infantil, gran impulsor de la ganancia de esperanza de vida media, habrá pasado de 48 niño fallecidos por cada 1000 nacidos en 1950 a 5 fallecidos por cada 1.000 nacidos. Todo un record . En 100 años habrá subido la esperanza de vida, habrá aumentado la edad media de los ciudadanos de la Unión Europea y habrá bajado drásticamente la mortalidad infantil. Ese es el panorama que se observa y se proyecta en la primera mitad del siglo XXI que acaba de comenzar (gráfico $\mathrm{n}^{\circ} 3$ ).

La Unión Europea tendrá en los próximos 50 años una subida de las tasas brutas de mortalidad como consecuencia del envejecimiento. Se prevé que en poco tiempo no solo haya tasa muy bajas de natalidad y mortalidad como ahora, sino que comience una transición demográfica a la inversa: bajas tasas de natalidad y alta tasas de mortalidad. La pérdida de la población que ese proceso va a provocar es tan obvia que la previsión media del gráfico $\mathrm{n}^{\circ} 1$ se puede quedar corta, siendo la hipótesis pesimista la más previsible. Los dato nos indican que en 100 años, 19502050, se habrá pasado de un 11 por 1.000 a un 14 por 1.000 de tasa bruta de mortalidad, y de un 18 por 1.000 a un 9 por 1.000 de tasa bruta de natalidad (gráfico $n^{\circ} 4$ ).

Las tasas generales brutas de natalidad y mortalidad tienen el inconveniente de que se dejan influenciar por la edad. La esperanza de vida y la tasa sintética de fecundidad son indicadores mucho más fiables porque no se dejan influenciar por la estructura de edad. La esperanza de vida ya la hemos visto. Fijémonos ahora en la tasa sintética de fecundidad así como en tasa bruta y tasa neta de reproducción. Se entiende por tasa sintética de fecundidad el $\mathrm{n}^{\circ}$ medio de hijos por mujer. El reemplazo de la población se da cuando esa tasa es de 2,1 hijos. En la Unión Europea hemos pasado de 2,4 hijos por mujer en 1950 a 1,44 en el quinquenio 1995-2000. Se tiene previsto un 1,8 en el año 2050. Desde el quinquenio 1970-1975 la tasa está por debajo del nivel de reemplazo. A partir del 2000 figura un leve ascenso hasta llegar al 1,8. Con estos dato resulta lógico que la población de la Unión pueda perder una 40 millones de persona el próximo medio siglo, a no ser que la inmigración no lo remedie. En demografía la mujer es fundamental. El panorama para la Unión Europea no es muy alagüeño. No solamente va a descender la población femenina en edad reproductiva, sino que la tasa bruta de reproducción, $\mathrm{n}^{\circ}$ medio de hijas por mujer, se mantendrá por debajo de 1, que es el nivel de reemplazo femenino. Para que la población se mantuviese estacionaria cada mujer tendría que dejar tras de si una hija, cosa que no ocurre desde el quinquenio 1975-1980. Se prevé que en el 2050 dicha tasa ascienda a 0,87 , pero siempre por debajo de 1 (gráfico $\mathrm{n}^{\circ} 5$ ). El descenso de la población en los próximos años parece lo más obvio, si la inmigración no lo remedia con subidas de la fecundidad. 
Este panorama poblacional que hemos descrito tiene unas consecuencias inmediatas, o mejor dicho, está teniendo unas consecuencias muy claras, consecuencias que hemos descrito de forma suscinta en la páginas iniciales: la inmigración que está teniendo lugar en los paíese de la UE. Una inmigración que no parará como consecuencia de la estructura joven de los países emisores, como los latinoamèricanos y los de la de la orilla sur del mediterráneo, con excedentes de población y con imposibilidad de que esos países de origen puedan ofrecerles unos mínimos de bienestar y seguridad económica a dicha población. El ejemplo del norte de Africa es claro.Alberga un potencial demográfico que ronda en el año 2000 alrededor de un 56\% de población menor de 25 años frente a un $29 \%$ de Europa (gráfico ${ }^{\circ} 6$ ). Esa población joven no tiene otra salida que Europa y Europa no tiene otra solución demográfica que absorber parte de esa población joven.

$\mathrm{El}$ indicador que antes hemos visto para España, referente a la edad media actual y futura, la podemos observar en la UE y en el norte de Africa. El resultado es claro: mientras que la orilla del sur mediterráneo pasará de 22 (2000) a 38 (2050) años de edad media, la edad media de la Unión Europea se incrementara de 29 a 49 años durante ese mismo período. Ricos pero viejos frente a pobres pero jóvenes, o sea el complemento (gráfico ${ }^{\circ} 8$ ). El ejemplo de Marruecos puede darnos pistas sobre el futuro comportamiento de la inmigración. En 1950 España tenía casi tres veces más población que el país magrebí. En el 2050 Marruecos nos superará con un $60 \%$ más de población. Los países más pobres del mundo doblaran en sólo cinco décadas su población.

Está claro que Europa en general y España en particular tendrán que recurrir masivamente a mano de obra inmigrante si quiera sea para mantener su población y garantizarles sus pensiones. En el año 2050 uno de cada 10 españoles tendrá más de 80 años. En el año 2000 Europa tiene una media de 4 a 5 personas en activo por cada jubilado. En el 2050 esa relación pasará a 2 activos por jubilado y en España a 1,4. Necesariamente esto supondrá un gran cambio en las estructuras demográficas y del mercado laboral. Dentro de Europa, las naciones que perderán más capital humano serán España e Italia.

Lo que hasta ahora hemos podido constatar es que seremos más viejos, viviremos más tiempo y alguien tendrá que cuidarnos y mantenernos. Ese mantenimiento podrá suponer un coste de hasta el $20 \%$ del producto interior bruto en Europa en los próximos 20 años. Constantemente se habla ya de que para rebajar ese coste y conservar la fuerza del trabajo ello puede suponer retrasar al edad de jubilación, rebajar las pensiones e incrementar la cotización social. Hay un problema añadido que consiste en la dificultad de ampliar el mercado de trabajo, saturado por el desempleo, para poder recibir mano de obra exterior que posibilite mantener la relación entre población activa y jubilados. 
Ante estas poco alagüeñas perspectivas cabe decir que los organismos internacionales y los propios nacionales afectados están tomando medidas. Un ejemplo es la Ley de Extranjería en España. Más vale tarde que nunca. El organismo internacional experto en población por antonomasia es La División de Población del Departamento de Asuntos Económicos y Sociales de Naciones Unidas, también ha contribuido a concretar este panorama difuso, publicando en Marzo del año 2000 un informe bajo el título "Migraciones de Reemplazo: ¿Una Solución ante la Disminución y el Envejecimiento de la Población?³ . El propio informe indica que el término migraciones de reemplazo se utiliza para definir el nivel de migraciones internacionales necesario en cada país para evitar la disminución y el envejecimiento de la población que resultan de tasas de natalidad y mortalidad bajas.

Lo que se propone Naciones Unidas es cuantificar el $n^{\circ}$ de inmigrantes necesarios para poder mantener cuatro de los escenarios que presenta $\left(\operatorname{tabla~}^{\circ} 4\right)$ :

1. En el primer escenario Naciones Unidas se pregunta por el número de inmigrantes que la Unión Europea necesitaría para mantener la población proyectada tomando como base la variante o hipótesis media. Esta variante supone que habrá un descenso de la población en los próximos 50 años de casi 40 millones de habitantes(grafico $\mathrm{n}^{\circ} 1$ ). A pesar del descenso el cálculo necesario es de 16,4 millones de inmigrantes, lo que supone la necesidad un flujo de entrada anual de 297 mil inmigrante entre 1995 y el 2050.

2. El segundo escenario que se plantea la $\mathrm{ONU}$ es el $\mathrm{n}^{\circ}$ de inmigrantes necesarios para poder mantener el $\mathrm{n}^{\circ}$ actual (año 2000) de habitantes (372,4 millones). Llega a la conclusión Naciones Unida que serían necesarios 47,4 millones de inmigrantes en las próximas cinco décadas, o un flujo de entrada anual de 863 mil inmigrantes en los próximos 50 años.

3. El tercer escenario que se plantea es el de cuantos inmigrantes serían necesarios en la Unión para mantener constante la población teóricamente activa actual (año 2000), la comprendida entre los 15 y lo 65 años. El resultado sería de 79,6 millones en el próximo medio siglo lo que supondría la necesidad de un flujo anual en ese período de 1.447 .000 inmigrantes.

4. Por último, si se quiere mantener constante durante los próximos 50 años la relación de 4 activos por jubilado, la cifra de inmigrantes necesarios se dispararía a niveles astronómicos: 700,5 millones, lo que supondría la necesidad de una entrada anual de casi 13 millones de inmigrantes en la Unión Europea durante los próximos 50 años.

Los propios expertos de la ONU dudan que Europa pueda resistir semejante terremoto social y opinan que la UE no puede asimilar tal cantidad de inmigrantes por ser políticamente arriesgado y socialmente inaceptable. Concluyen que, sin llegar a esa cifras, el fenómeno ocurrirá de todas formas. 
Una de las mas llamativas e interesantes conclusiones del informe de la ONU es que en ausencia de inmigración, los cocientes de dependencia potencial podrían mantenerse en los niveles actuales si se desplazase la edad de jubilación a los 75 años aproximadamente.

El informe concluye con la necesidad de que los nuevos retos que presenta la disminución y el envejecimiento de la población requieren una revisión general de numerosa políticas y programas existentes, desde una visión a largo plazo. Entre lo aspecto que necesitan un nuevo planteamiento están:

1. La edad de la jubilación.

2. Los niveles y tipos de pensiones de jubilación y salud para la gente mayor.

3. La participación en las fuerza de trabajo.

4. La contribución de los trabajadores y empresarios a las pensiones de jubilación y salud para la gente mayor.

5. Las políticas y programas de inmigración, especialmente en relación a las migraciones de reemplazo y a la integración de contigentes importantes de inmigrante y sus descendientes.

Ya en 1992 se escribió:

Es impensable que en España no exista un gran centro de seguimiento de Africa, donde se estudie cada día sus movimiento y corrientes. Ejemplos: España podía contribuir a la creación de un gran programa hidráulico en Marruecos, a condición de pactar con el gobierno de Rabat un programa de cuotas anuales de emigrantes, con determinación precisa de la cualificación profesional de cada uno de ellos y su situación familiar (todos tratan de incorporar antes o después a su familia). Digámoslo una vez más: la CE debe acordar una política migratoria común. Lo cual reclama un acuerdo para avanzar hacia una política exterior común en lo que por ahora se ha fracasado ${ }^{4}$.

En el año 2001 no parece que esta petición se haya tenido en cuenta. Faltan centros especializados donde se haga seguimiento de la población, fundamentalmente latinoamericana. España debe apostar por Hispanoamérica en su política inmigratoria. Lengua y cultura es el argumento básico para esta decisión. Tendremos que saber cuantos hay, su estructura, sus movimientos y corrientes. Es esta una nueva ocasión para que los nuevos centros universitarios de reciente creación sean sensibles a lo que en la sociedad más está preocupando en estos momento. Esa sensibilidad debe transformarse en una política de creación de Departamentos e Institutos universitarios donde se hagan seguimiento de los problemas sociológicos de la población, trabajando con un criterio que permita una inmigración inteligente, con todo lo que esa inteligencia puede aportar de innovación y energía al país de acogida. La creación de esos centros son tan necesarios como necesario es acometer un futuro demográfico que deviene incierto. Todavía se está a tiempo. 


\section{ANEXO TABLAS}

Tabla 1. Los 10 países del mundo con la edad media más joven y más vieja en el año 2.000 y en el 2.050

\begin{tabular}{|c|c|c|c|}
\hline \multicolumn{2}{|c|}{2000} & \multicolumn{2}{|c|}{2050} \\
\hline países* & Edad media & Países* & Edad media \\
\hline
\end{tabular}

A. Población más vieja

$\begin{array}{llll}\text { 1. Japón } & 41,2 & \text { 1. ESPAÑA } & 55,2 \\ \text { 2. Italia } & 40,2 & \text { 2. Eslovenia } & 54,1 \\ \text { 3. Suiza } & 40,2 & \text { 3. Italia } & 54,1 \\ \text { 4. Alemania } & 40,1 & \text { 4. Austria } & 53,7 \\ \text { 5. Suecia } & 39,7 & \text { 5. Armenia } & 53,4 \\ \text { 6. Finladia } & 39,4 & \text { 6. Japón } & 53,1 \\ \text { 7. Bulgaria } & 39,1 & \text { 7. Repub. Checa } & 52,4 \\ \text { 8. Bélgica } & 39,1 & \text { 8. Grecia } & 52,3 \\ \text { 9. Grecia } & 39,1 & \text { 9. Suiza } & 52,0 \\ \text { 10. Dinamarca } & 38,7 & \text { 10. China } & 51,9\end{array}$

B. Población más joven

$\begin{array}{llll}\text { 1. Yemen } & 15,0 & \text { 1. Niger } & 20,4 \\ \text { 2. Niger } & 15,1 & \text { 2. Yemen } & 21,1 \\ \text { 3. Uganda } & 15,4 & \text { 3. Angola } & 21,2 \\ \text { 4. Burkina Faso } & 15,6 & \text { 4. Somalia } & 21,5 \\ \text { 5. Rep. Congo } & 15,6 & \text { 5. Uganda } & 22,1 \\ \text { 6. Angola } & 15,9 & \text { 6. Burkina Faso } & 22,8 \\ \text { 7. Somalia } & 16,0 & \text { 7. Liberia } & 22,9 \\ \text { 8. Burundi } & 16,0 & \text { 8. Mali } & 22,9 \\ \text { 9. Zambia } & 16,5 & \text { 9. Burundi } & 23,2 \\ \text { 10. Benin } & 16,6 & \text { 10. Malawi } & 23,7\end{array}$

MUNDO

26,5

MUNDO

36,2

Fuente: Elaboración propia con datos de United Nations Population Division, Worl Poulation Prospects :The 2.000 revision (28 febrero 2.001)

* Países con más de 140.000 habitanten o más en el año 2.000 . 
Tabla 2. Los 10 países del mundo con el mayor y el menor porcentaje de población mayor de 60 año en el año 2.000 y en el 2.050 :

\begin{tabular}{|c|c|c|c|}
\hline \multicolumn{2}{|c|}{2.000} & \multicolumn{2}{|c|}{2.050} \\
\hline PAÍSES* & $\% 60 y+a \tilde{n} o s$ & PAÍSES* & $\% 60 y+a \tilde{n} o s$ \\
\hline TOTAL & & TOTAL & \\
\hline MUNDIAL & 10,0 & MUNDIAL & 21,1 \\
\hline \multicolumn{4}{|c|}{ A. Países más viejos } \\
\hline Italia & 24,1 & ESPAÑA & 44,1 \\
\hline Grecia & 23,4 & Eslovenia & 42,4 \\
\hline Alemania & 23,2 & Japón & 42,3 \\
\hline Japón & 23,2 & Italia & 42,3 \\
\hline Suecia & 22,4 & Austria & 41,0 \\
\hline Bélgica & 22,1 & Grecia & 40,7 \\
\hline ESPAÑA & 21,8 & República Che & 40,1 \\
\hline Bulgaria & 21,7 & Armenia & 39,5 \\
\hline Suiza & 21,3 & Suiza & 38,9 \\
\hline Latvia & 20,9 & Bulgaria & 38,6 \\
\hline \multicolumn{4}{|c|}{ B. Países más jóvenes } \\
\hline Qatar & 3,1 & Niger & 5,0 \\
\hline Niger & 3,3 & Angola & 5,2 \\
\hline Yemen & 3,6 & Yemen & 5,3 \\
\hline Uganda & 3,8 & Somalia & 5,7 \\
\hline Somalia & 3,9 & Uganda & 5,7 \\
\hline Tanzania & 4,0 & Djibouti & 5,8 \\
\hline P. N. Guinea & 4,1 & Congo & 6,2 \\
\hline Kenya & 4,2 & Burkina Faso & 6,5 \\
\hline Solomon Is lan & 4,2 & Malawi & 6,6 \\
\hline Rwanda & 4,2 & Ethiopia & 6,6 \\
\hline
\end{tabular}

Fuente:Elaboración propia a partir dr los datos que proporciona: United Nations Population Division, World Population Prospects: The * Países con más de 140.000 en el 2.000. 
Tabla 3. Los 10 países del mundo con las tasas de crecimiento natural más altas y más bajas entre el 2000-2005 y el 2045-2050.

\begin{tabular}{ccccc}
\hline & & & $2045-2050$ \\
\cline { 1 - 1 } \cline { 5 - 6 } Países* & Tasa de & & Tasas de \\
& crecimiento & & Países* \\
& natural (\%) & & crecimiento \\
& & & natural (\%) \\
\hline
\end{tabular}

Tasa de crecimiento natural más alta

$\begin{array}{llll}\text { 1. Liberia } & 4,32 & \text { 1. Yemen } & 2,45 \\ \text { 2. Yemen } & 4,05 & \text { 2. Niger } & 2,38 \\ \text { 3. Niger } & 3,61 & \text { 3. Somalia } & 2,20 \\ \text { 4. Somalia } & 3,48 & \text { 4. Angola } & 2,11 \\ \text { 5. Teritorio palestino ocup. } & 3,47 & \text { 5. Uganda } & 1,92 \\ \text { 6. República Demo. Congo } & 3,36 & \text { 6. Burkina Faso } & 1,88 \\ \text { 7. Uganda } & 3,34 & \text { 7. Liberia } & 1,88 \\ \text { 8. Mali } & 3,23 & \text { 8. Mali } & 1,84 \\ \text { 9. Angola } & 3,22 & \text { 9. Etiopia } & 1,63 \\ \text { 10. Oman } & 3,19 & \text { 10. Burundi } & 1,61\end{array}$

B. Tasa de crecimiento natural más baja
1. Ucrania
$-0,73$
1. Italia
$-1,12$
2. Bulgaria
$-0,72$
2. ESPAÑA
$-1,04$
3. Federación Rusa
$-0,67$
3. Eslovenia
$-0,97$
4. Latvia
4. Ucrania
$-0,93$
5. Belarus
5. Bosnia-Herzegovina
$-0,93$
6. Hungría
$-0,50$
6. Suiza
$-0,93$
7. Estonia
$-0,46$
7. Austria
$-0,90$
8. Alemania
8. Bulgaria
$-0,87$
9. Suecia
9. Federación Rusa
$-0,87$
10. Lituania
$-0,24$
10. Grecia
$-0,82$
TOTAL MUNDO
1,23
TOTAL MUNDO
0,47

Fuente: Elaboración propia tomando datos de: United Nations Population Division, World Population Prospects, (N.Y. 21 de Febrero de 2.001) 


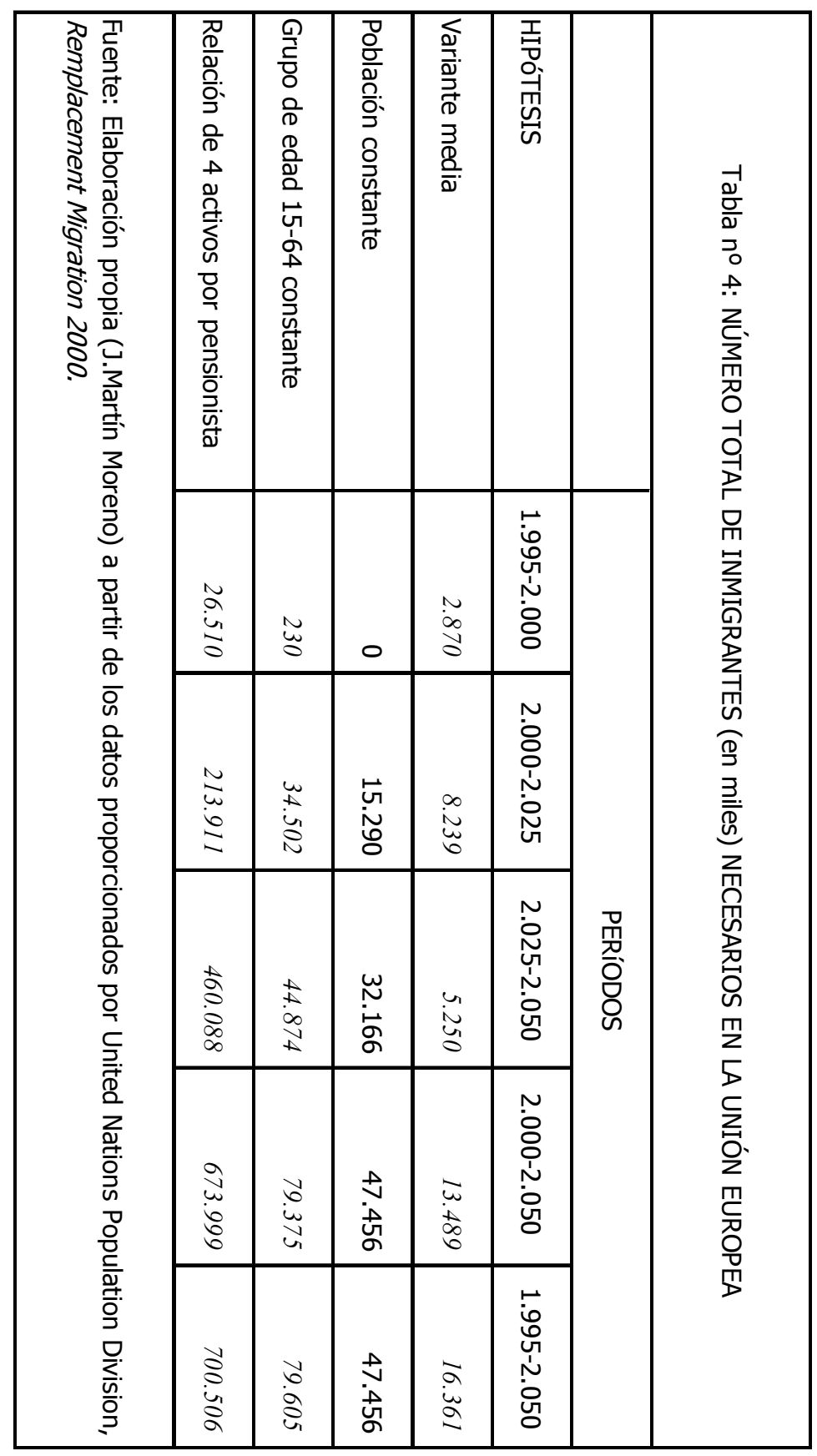




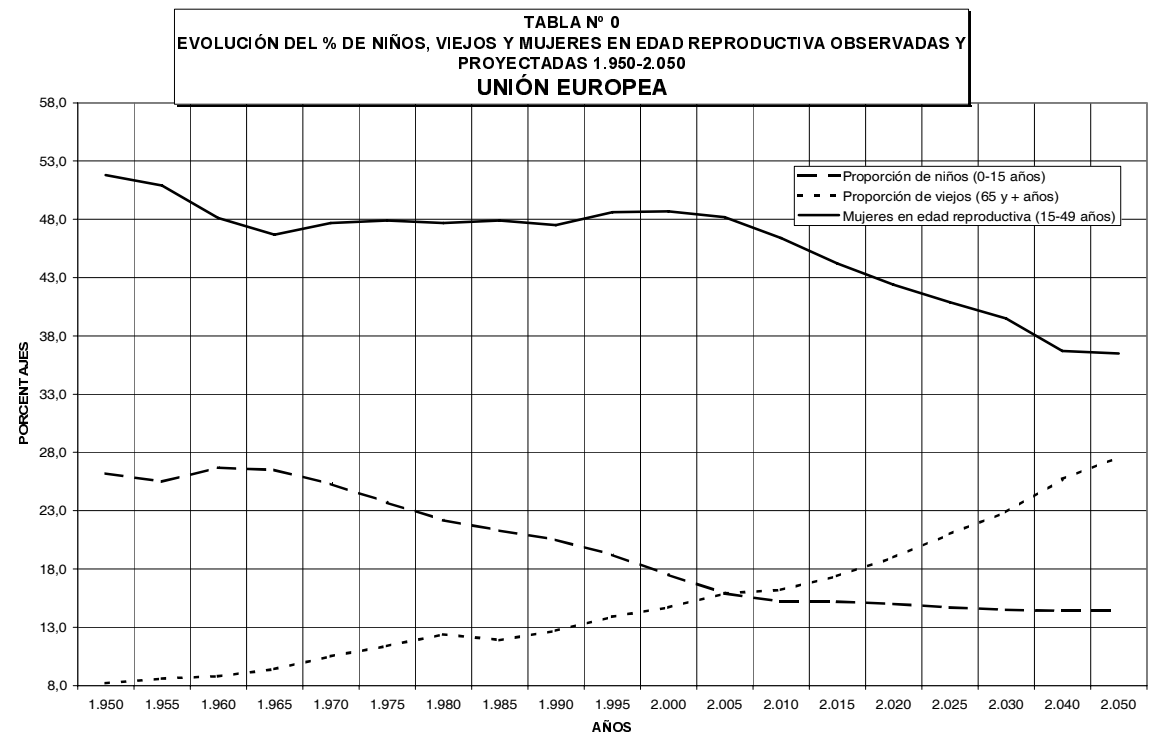

GRÁFICO No1

POBLACIÓN OBSERVADA Y PROYECTADA EN LA UNIÓN EUROPEA SEGÚN HIPÓTESIS ALTA, MEDIAY BAJA

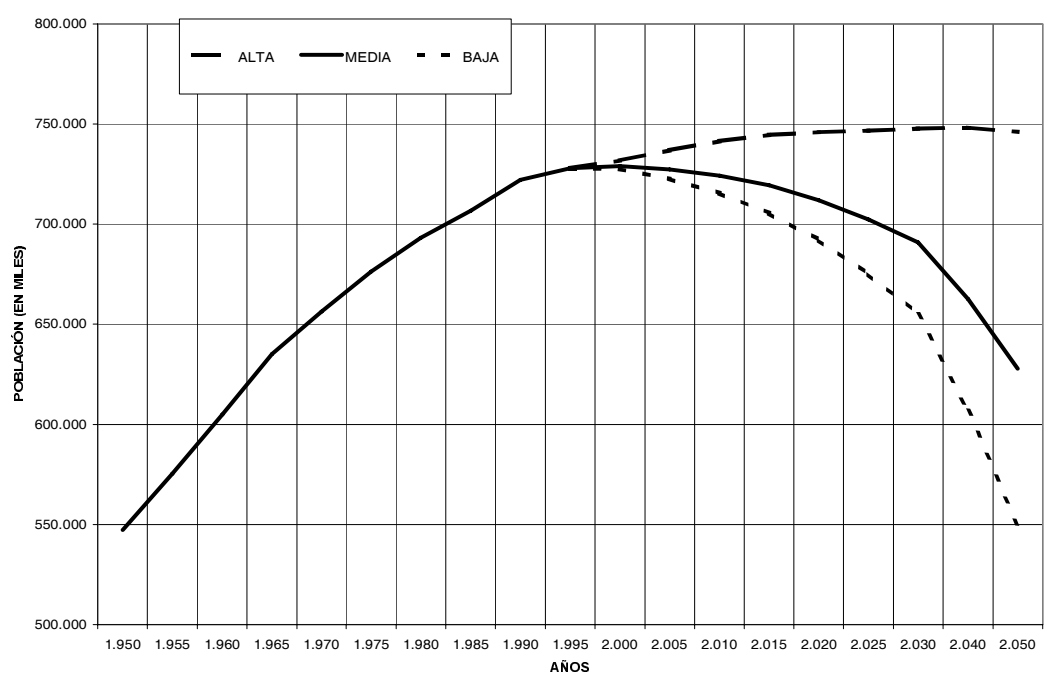


GRÄFICO $\mathrm{N}^{\circ} 2$

PROYECCÓNDE LAPIRÁMDE DE POBLACÓNEUROPEA: 2000-2050

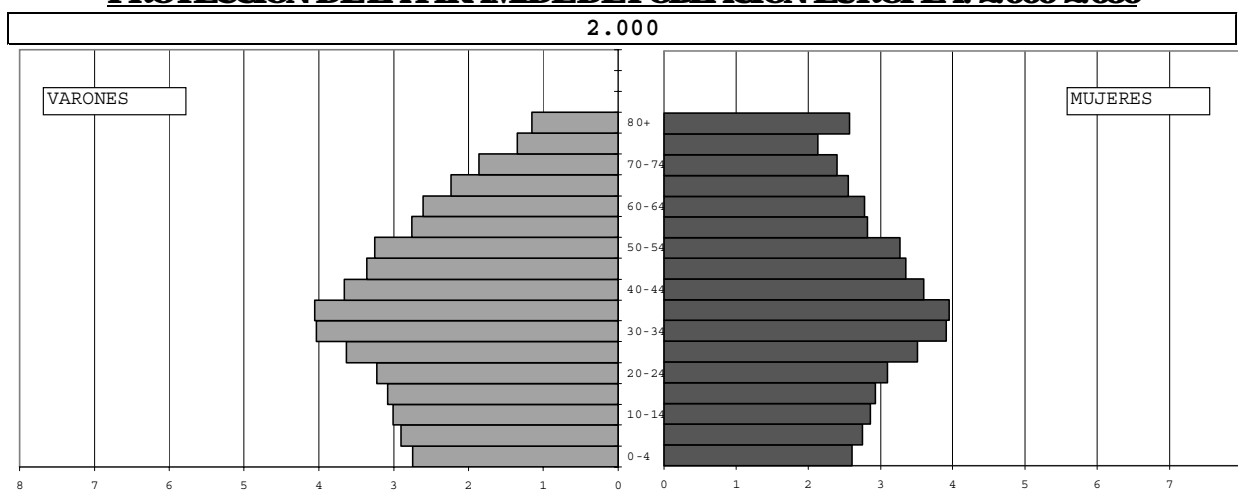

2.025

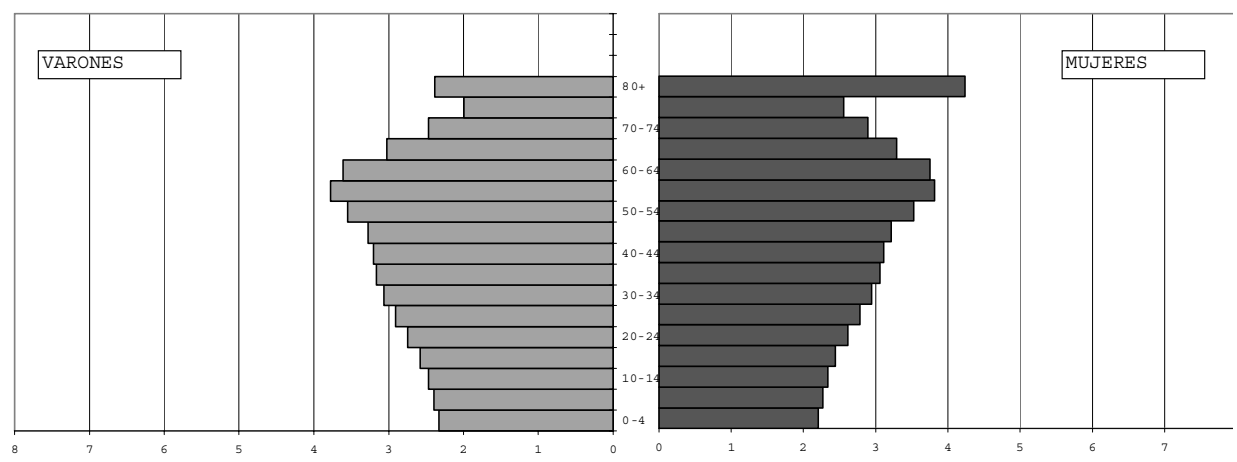

2.050

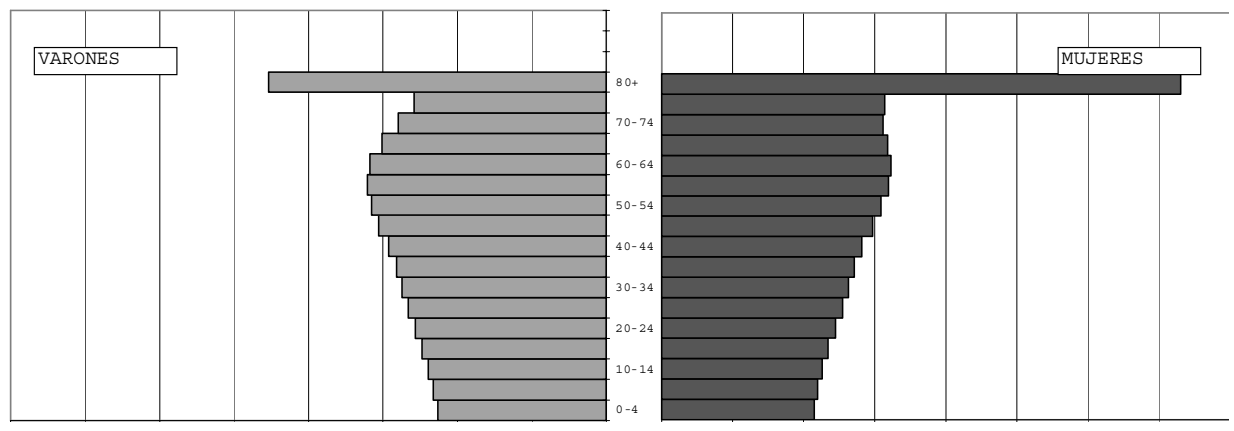




\section{GRÁFICO No 3}

Esperanza de vida y mortalidad infantil observadas y proye ctadas

(1.950-2.050)

UNIÓN EUROPEA

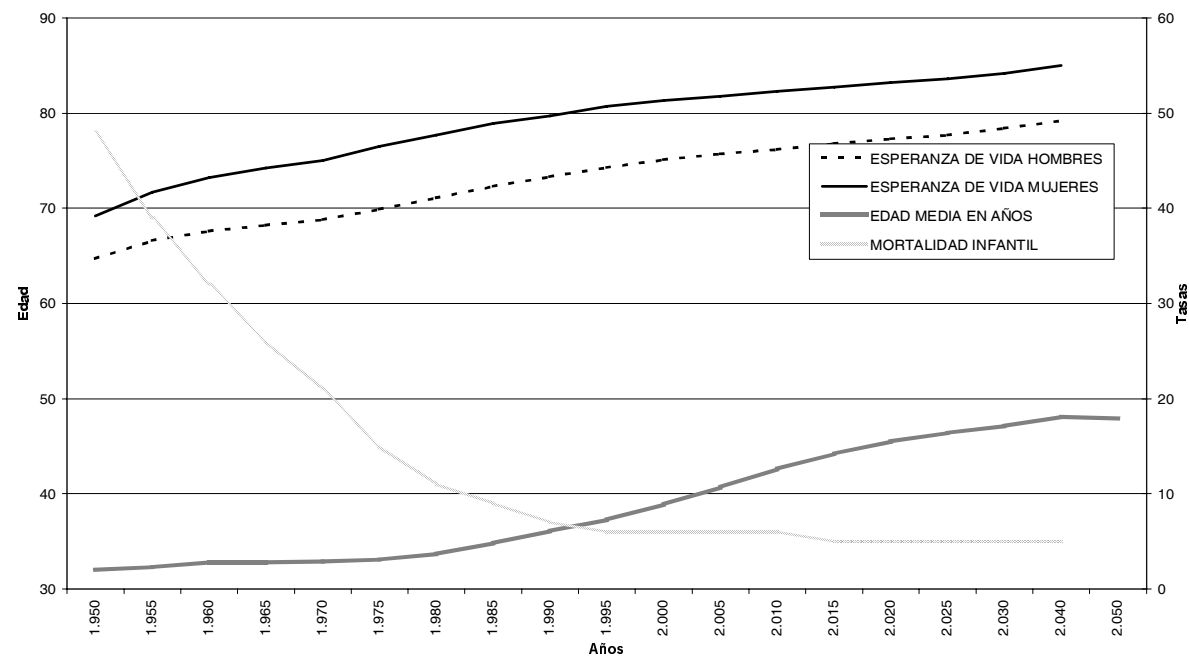

GRÁFICO No 4

Tasas brutas de natalidad y mortalidad observa das y proyectadas

(1.950-2.050)

UNIÓN EUROPEA

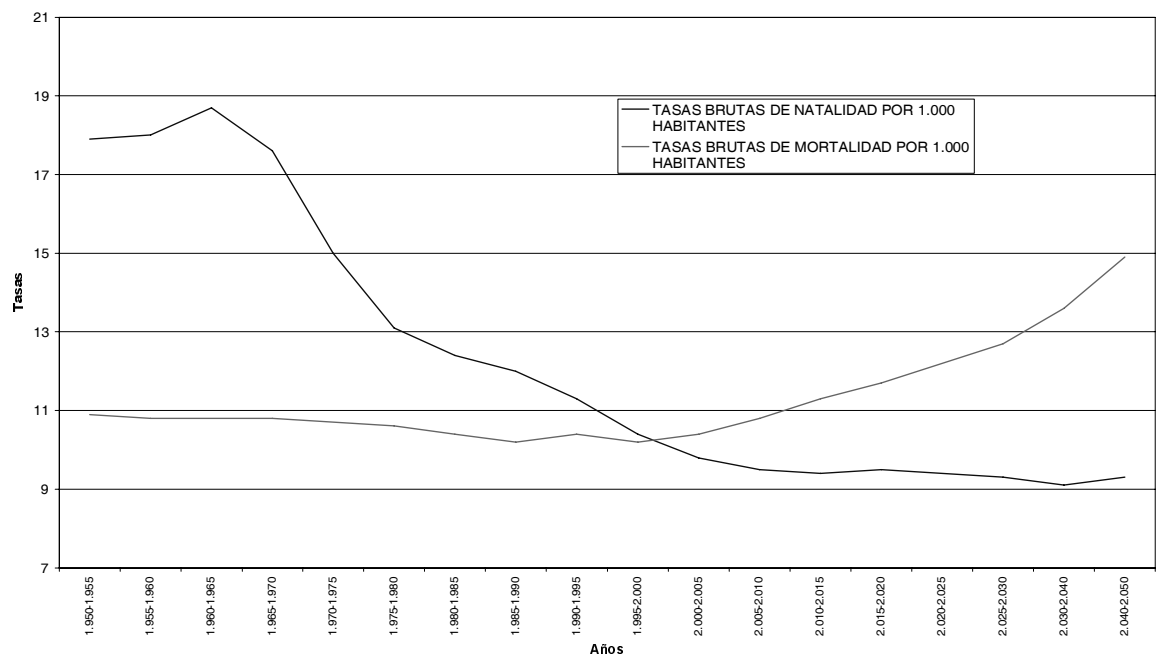



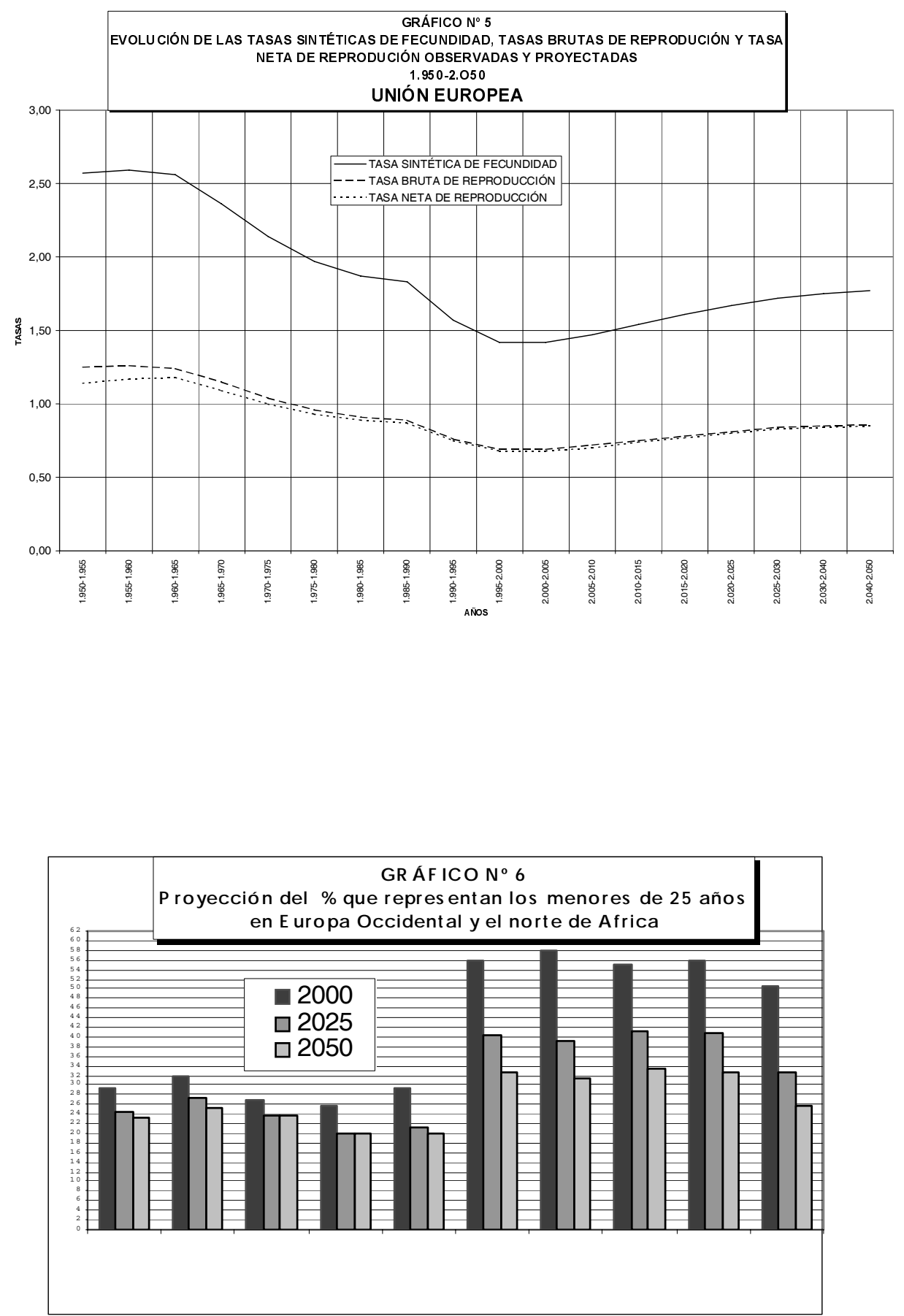
GRÁFICO № 7

EDAD MEDIA OBSERVADA Y PROYECTADA EN ALGUNOS PAÍSES EUROPEOS Y AFRICANOS: 2.000-2.050

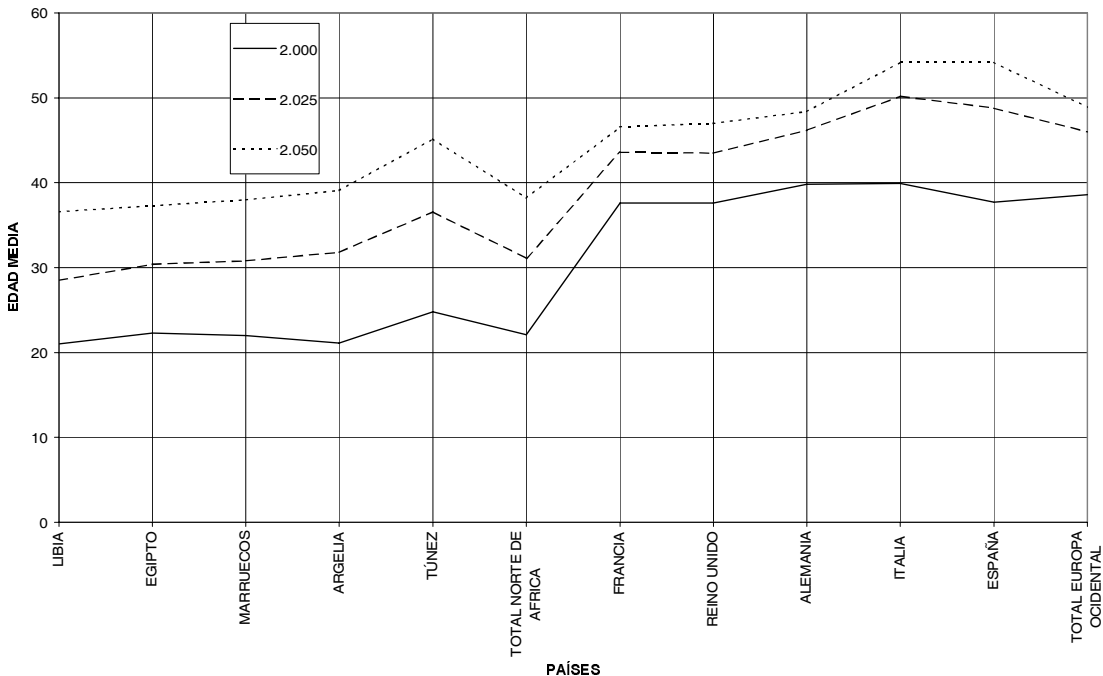

\% POBLACIÓN MAYOR ( $60 \mathrm{y}+$ años) OBSERVADA Y PROYECTADA(\%) EN ALGUNOS PAÍSES EUROPEOS Y AFRICANOS: $2.000-2.050$

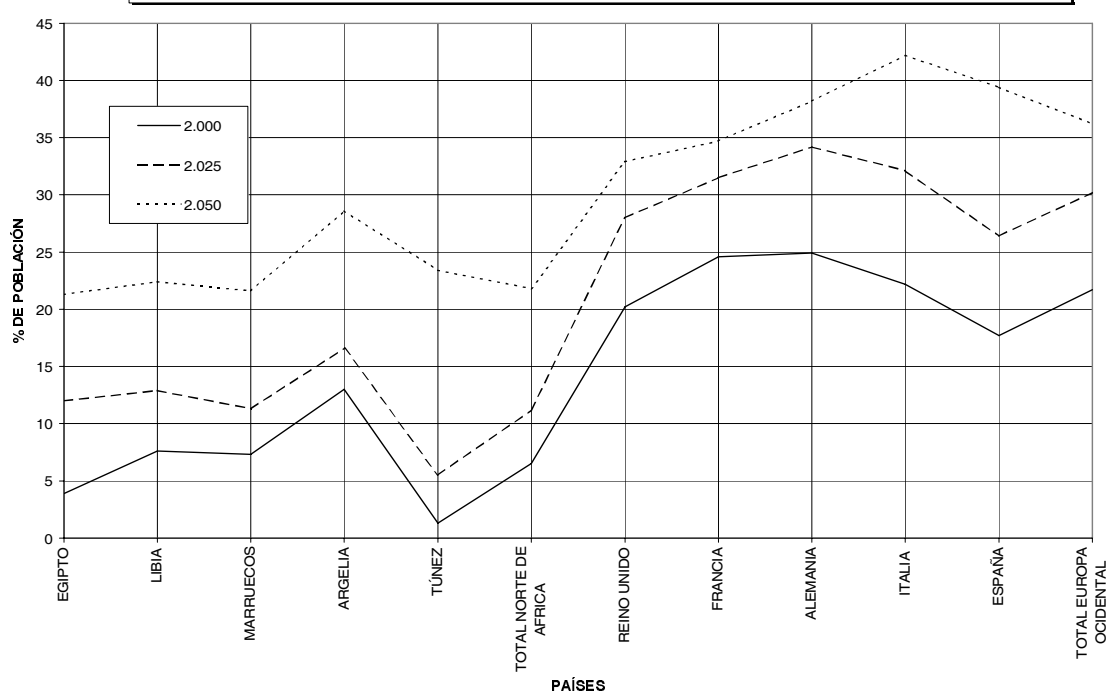




\section{NOTAS}

${ }^{1}$ Este artículo es una versión ampliada de la conferencia que el autor impartió en Julio del año 2.000 en el curso "IDEAS PARA EL SIGLO XXI", dirigido por el Catedrático de Sociología Prof. Doctor D. Octavio Uña, con ocasión de los cursos de verano que la Universidad Rey Juan Carlos celebra todos los años en Ronda. El título original de la conferencia fue: "Los cambios en la estructura de la población y las migraciones".

${ }^{2}$ Parada, I. 2000

${ }^{3}$ Population Division United Nations Replacement Migration: Is It a Solution to Declining and Ageing Populations? (2000)

${ }^{4}$ Valcárcel, D. 1.992

\section{BIBLIOGRAFÍA}

Parada, I. en $A B C(2-4-2000)$

Population Division United Nations, Replacement Migration:Is It a Solution to Declining and Ageing Populations? (2000)

United Nations, Fertility trends among low fertility countries. In the Proceedings on Expert Group Meeting on Below-replacement Fertility, New York: 4-6 November 1997. United Nations,. World Population Monitoring 1997: International Migration and Development. 1998.

United Nations, Trends in Total Migrant Stock by Sex. Database maintained by the Population Division, Department of Economic and Social Affairs. 1998

United Nations, World Population Prospects: The 1998 Revision, vol. 1, Comprehensive Tables. 1999

United Nations, World Population Prospcts: The 1998 Revision, vol. II, Sex andAge. 1999. United Nations, World Population Prospects: The 1998 Revision, vol. III, Analytical Report. 1999

United Nations, World Population Prospects: The 2000 Revision, vol. III, Analytical Report. 1999

Valcárcel, D., en $A B C$ (1-12-1992) 